\title{
Chronic Obstructive Pulmonary Disease Mismatch: A Case of Tracheal Hamartoma
}

\author{
Aleksandar M. Ivanovic ${ }^{a, b}$ Ruza Stevic ${ }^{a, b}$ Marko Popovic ${ }^{c}$ Jelena Stojsic ${ }^{d}$ \\ Dragan Masulovic ${ }^{a, b}$ Radoslav Jakovic ${ }^{a, c}$ \\ ${ }^{a}$ Faculty of Medicine, University of Belgrade, and ${ }^{b}$ Center of Radiology and Magnetic Resonance Imaging, ${ }^{c} \mathrm{Clinic}$ for \\ Thoracic Surgery, and ${ }^{d}$ Department of Pathology, Clinical Center of Serbia, Belgrade, Serbia
}

\section{Keywords}

Tracheal neoplasms · Chronic obstructive pulmonary

disease · Hamartoma - Computed tomography

\begin{abstract}
Objective: To demonstrate the diagnostic challenge of tracheal hamartoma in a patient with chronic obstructive pulmonary disease (COPD). Clinical Presentation and Intervention: A 65-year-old man with COPD was admitted with sudden onset of asphyxia attacks related to the position of his body. Computerized tomography (CT) of the neck showed a soft tissue mass with calcification, which occluded more than two-thirds of the proximal part of the trachea. The tumor was completely removed, and histopathology confirmed hamartoma. Conclusion: This case report showed the detection of a primary tracheal tumor on CT. This finding enabled the correct diagnosis and led to appropriate treatment in the form of surgery.

(c) 2016 S. Karger AG, Basel
\end{abstract}

\section{Introduction}

Primary tracheal tumors comprise $<1 \%$ of all tumors and benign tumors are less common than malignant tracheal tumors [1]. Hamartoma, a benign tumor of mesen- chymal origin, is extremely rare, with $<20$ adult cases to be found in the literature [2]. Due to signs and symptoms that mimic chronic obstructive pulmonary disease (COPD), there is usually a delay in diagnosing this tumor [3]. A common localization is the margin of the membranous and cartilaginous part of the tracheal wall. Here, we report a case that arose completely from the cartilaginous tracheal wall.

\section{Case Report}

A 65-year-old male patient was admitted to the clinic for thoracic surgery due to asphyxia attacks in the supine position, which forced him to sleep in a sitting position. He had a 2 -year history of progressive dyspnea and fatigue that worsened when he was walking on an incline and when leaning forward. For several years, he had been treated in a regional health center based on a diagnosis of COPD with partial response. Posterior-anterior radiography performed at this center showed signs of COPD as well as tracheal stenosis at level C4-5.

At admission, he was breathing heavily with a characteristic inspiratory wheezing and using the auxiliary respiratory musculature due to heavy inspirations. During physical examination, a palpable mass was found, approximately $2 \mathrm{~cm}$ in diameter, on the left side of the neck next to the trachea. Spirometric findings showed moderate insufficiency of ventilation with a flow/volume curve flattened in the inspiratory and the expiratory phases, indicating a fixed central airway obstruction. Multidetector CT examination of the neck at the proximal part of the trachea showed a soft tissue

\section{KARGER}

E-Mail karger@karger.com www.karger.com/mpp

\section{(c) 2016 S. Karger AG, Basel}

Karger

This is an Open Access article licensed under the terms of the Creative Commons Attribution-NonCommercial 3.0 Unported license (CC BY-NC) (www.karger.com/OA-license), applicable to the online version of the article only. Distribution permitted for non-commercial purposes only.
Aleksandar M. Ivanovic

Center of Radiology and Magnetic Resonance Imaging, Clinical Center of Serbia Faculty of Medicine, University of Belgrade, Jurija Gagarina St. 220/59 RS-11070 Belgrade (Serbia)

E-Mail alexivanovic69@yahoo.com 

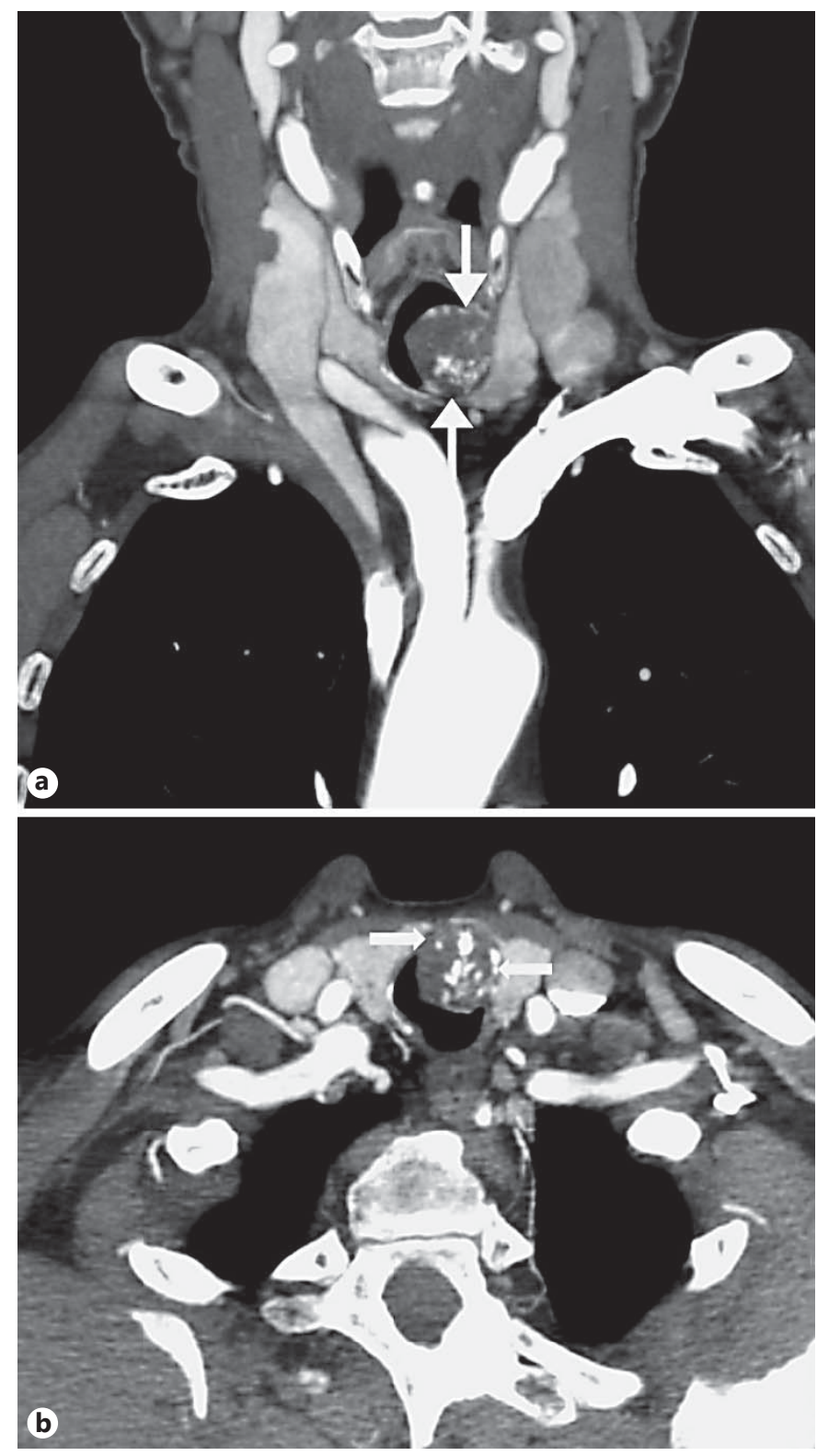

Fig. 1. a Contrast-enhanced multidetector CT of the neck reveals a soft tissue mass with calcification, approximately $2 \mathrm{~cm}$ in diameter (arrows) at the proximal part of the trachea. $\mathbf{b}$ The mass, with a broad base, abuts the anterior and left side of the tracheal cartilage (arrows) and occludes more than two-thirds of the initial lumen.

mass with calcification, approximately $2 \mathrm{~cm}$ in diameter, with a broad base abutting the anterior and left side of the tracheal cartilage. The mass occluded more than two-thirds of initial lumen (Fig. 1a, b). Rigid preoperative bronchoscopy using general anesthesia showed a pale pink tumor that involved $4 / 5$ of the tracheal lumen and a broad base connected with the third tracheal ring, while the membrane wall was completely free of it. During dissec-

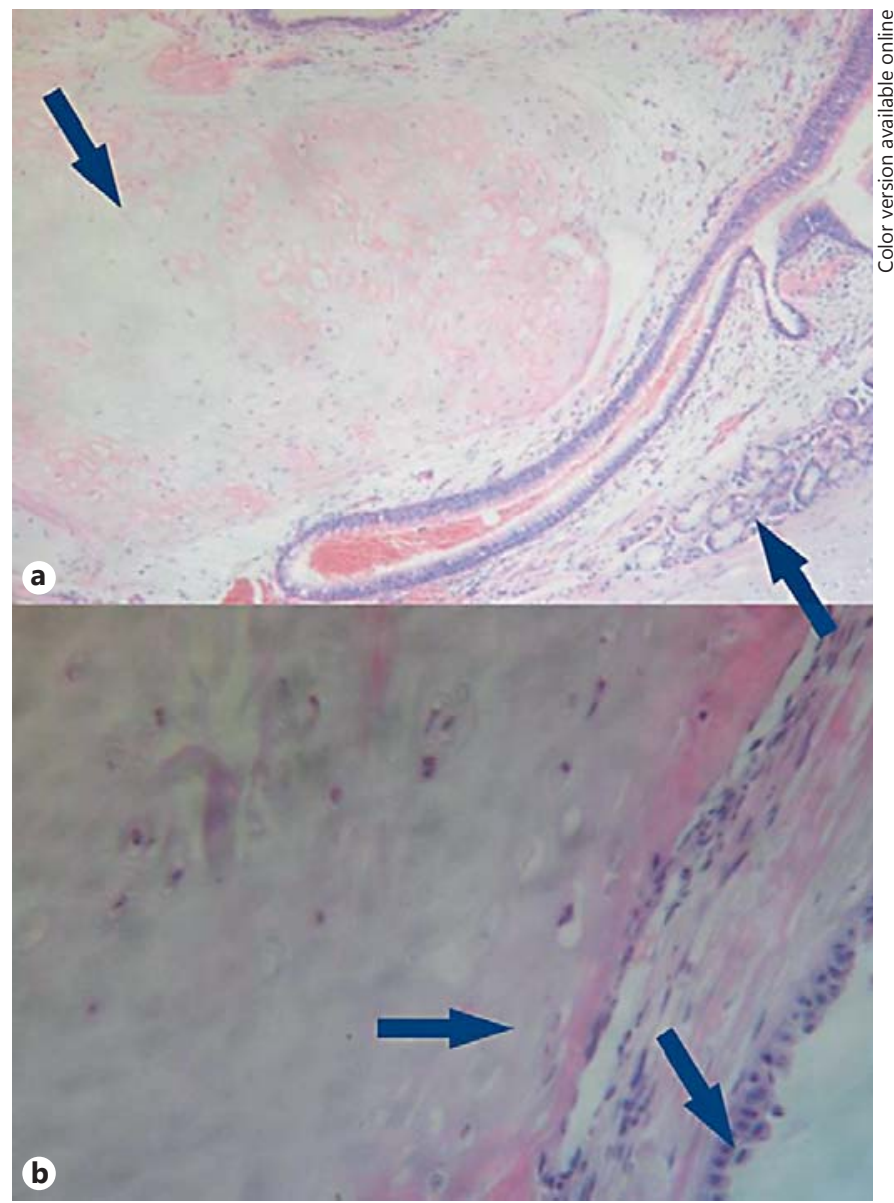

Fig. 2. The cartilaginous part of the hamartoma protrudes into the tracheal lumen. a Tracheal glands are seen in the lower right corner. b Detail of the tumor. The hamartoma is settled in tracheal mucosa and covered by intact respiratory epithelium.

tion of the trachea, it was determined that the tumor neither protruded the tracheal wall nor infiltrated the surrounding tissue. Partial resection of the trachea was done in block, and the tumor involved 2 tracheal rings which corresponded to hamartoma in its macroscopic features. T-T anastomosis of the trachea was done with individual stitches.

On histopathologic examination, it was seen that the tumor was growing with its wide petiole from the cartilaginous tracheal wall. The presence of mesenchymal structures confirmed the diagnosis of tracheal hamartoma with chondromatous and lipomatous components (Fig. 2).

The postoperative course was uneventful and clinical and radiographic signs of tracheal obstruction were not seen at regular follow-up appointments. Three months after surgery, postoperative spirometry showed no physiologically significant narrowing of the upper airways but there were still signs of moderately expressed obstruction, which supported the previous diagnosis of COPD, with FVC 87\% (3.36 L) and $\mathrm{FEV}_{1}$ 59\% (1.79 L). 


\section{Discussion}

The patient in the case presented here had had a history of progressive dyspnea for 2 years and had been treated without benefit according to a diagnosis of COPD. His unresponsiveness to bronchodilatator therapy led us to consider fixed main airway obstruction and to conduct other diagnostic tests. Spirometry with the expected flow/ volume curve $[3,4]$ findings of a calcifying soft tissue mass on imaging modalities and bronchoscopy confirmed the diagnosis [5].

If obstructive tracheal lesions are masked by the presence of COPD or asthma, as in this and previously reported cases, they are very difficult to diagnose. Conventional chest radiography as a first diagnostic test can lead to a tracheal tumor being overlooked due to its coexistence with COPD [6-8]. Sudden onset of shortness of breath and wheezing related to the position of the body should arouse suspicion of obstruction of the central airways, as in our case. Due to the slow-growing nature of hamartoma, the symptoms can be mild and negligible for years $[7,8]$. Benign tracheal tumors, such as hamartoma, have a heterogeneous histological appearance and do not occur after complete resection [6]. Therefore, only surgical treatment is performed.

\section{Conclusion}

This case report showed detection of a primary tracheal tumor on CT. This finding enabled correct diagnosis and led to appropriate treatment in the form of surgery.

\section{Acknowledgement}

The authors dedicate this paper to the late Radoslav Jakovic, Professor of Thoracic Surgery, Faculty of Medicine, University of Belgrade, Belgrade, who inspired and encouraged us to aim for greater heights.

\section{References}

1 Macchiarini P: Primary tracheal tumours. Lancet Oncol 2006;7:83-91.

2 Panagiotou M, Kalkanis A, Karagiannidis N, Polychronopoulos V: A case of tracheal hamartoma resected with loop electrocautery. Case Rep Pulmonol 2013;2013:568590.

3 Miller WT: Obstructive diseases of the trachea. Semin Roentgenol 2001;36:21-40.
4 Pellegrino R, Viegi G, Brusasco V, et al: Interpretative strategies for lung function tests. Eur Respir J 2005;26:948-968.

5 Wu CC, Shepard JAO: Tracheal and airway neoplasms. Semin Roentgenol 2013;48:354364.

6 Gaissert HA, Grillo HC, Shadmehr MB, et al: Uncommon primary tracheal tumors. Ann Thorac Surg 2006;82:268-273.
7 Cetinkaya E, Gunluoglu G, Eyhan S, et al: A hamartoma located in the trachea. Ann Thorac Cardiovasc Surg 2011;17:504-506.

8 Kunisawa A, Ichinose Y, Kiyokawa H, et al: Tracheal hamartoma detected by abnormal breath sounds. J Bronchol 2000;7:160-163. 